Philosophy and Progress: Vols. LXI-LXII, January-June, July-December, 2017 ISSN 1607-2278 (Print), DOI : https://doi.org/10.3329/pp.v61i1-2.44208

\section{A CRITICAL STUDY OF ROBERT NOZICK'S VIEW ON UTILITARIANISM}

\begin{abstract}
Sajia Afrin ${ }^{*}$
In this paper, I will analyze and critically evaluate $20^{\text {th }}$ century American philosopher Robert Nozick's position regarding utilitarianism; how he refutes utilitarianism with reference to two new concepts called "Experience Machine" and "Utility Monster". I will argue that if we were given the option of entering into an experience machine as Nozick presented in his book Anarchy State and Utopia, in which we can create a new better life for ourselves, then it would be irrational to refuse the option. I will then reply to Nozick's objection regarding utilitarianism within his concept of utility monster, where he argued that accepting the theory of utilitarianism causes the necessary acceptance of a utility monster, that is, the condition that some people would use this doctrine to justify the exploitation of others. I will argue here that giving "happy units" to weak utility monsters can bring about wonderful result. All my arguments are formed within utilitarian consequentialist framework.
\end{abstract}

\footnotetext{
* Lecturer, Department of Philosophy, Jagannath University

E-mail : afrinsajia718@gmail.com
}

\section{The Experience Machine}

The Experience Machine is a thought experiment which was put forward by Robert Nozick in his 1974 book Anarchy State and Utopia. It is one of the best known attempts to refute utilitarianism. Utilitarianism is the doctrine which states that the best action is the one that maximizes utility. This doctrine has been highly criticized throughout the history as "a doctrine worthy of swine". (Mill, Ch.2, p.4) According to J.S Mill, the actions are right as they tend to promote happiness and wrong as they tend to promote unhappiness. (Mill, Ch.2, p.3) The ultimate goal in life is pleasure and happiness, the opposite of which is pain and unhappiness. So, pleasure is the only thing which is intrinsically valuable. When the critics say that utilitarianism is a doctrine worthy of swine, they are objecting to the proposition that "pleasure is the only end". Their criticism, according to Mill, says "To suppose that life has (as they express it) no higher end than pleasure- no better and nobler object of desire and pursuit- they designate as utterly mean and groveling; as a doctrine worthy only of swine." (Mill, Ch.2, p.3) They are referring to physical pleasures only ignoring the intellectual pleasures. The Epicureans respond to the objections of the critics by pointing out that they are making a mistake in assuming that attaining physical pleasures is the only goal of human life ignoring the higher pleasures. The Epicureans go further by arguing that even if physical pleasures were the ultimate end of human life, still then pleasure would be the ultimate end of human life. Jeremy Bentham was another defender of utilitarianism. According to him, humans are different from animals because humans seek other type of pleasures, which are not limited to physical pleasures only. The best act is one that produces the greatest amount of pleasure for the greatest number of people. 
Nozick attacks this doctrine of utilitarianism by means of his experience machine thought experiment. In the experience machine, Nozick proposes a hypothetical position in which humans have the option to plug into a machine that would give him any pleasure he wants. When he plugs into the machine he would have no idea that what was happening was not real. $\mathrm{He}$ can do, feel and experience anything he wants to; he can achieve a state of total bliss and happiness. For example, I can program a life for myself in which I am a successful businessman. Once I enter the machine I lose all my memory of entering the machine and believe that the simulated reality is the real one. Nozick argues that if it were the case that "pleasure is the only end", then living in the simulated reality would be a person's best choice. But most people would not choose to plug into the machine because there are more things that matter to us than the way we feel. There is something other than pleasure that has value in human life. Nozick originally described the experience machine thought experiment as follows:

Suppose there were an experience machine that would give you any experience you desired. Super duper neuropsychologists could stimulate your brain so that you would think and feel you were writing a great novel, or making a friend, or reading an interesting book. All the time you would be floating in a tank, with electrodes attached to your brain. Should you plug into this machine for life, preprogramming your life's experiences? If you are worried about missing out on desirable experiences we can suppose that business enterprises have researched thoroughly the lives of many others. You can pick and choose from their large library or smorgasbord of such experiences, selecting your life's experiences for, say, the next two years. After two years have passed, you will have ten minutes or ten hours out of the tank, to select the experiences of your next two years. Of course, while in the tank you won't know you're there; you'll think it's all actually happening. Others can also plug in to have the experiences they want, so there's no need to stay unplugged to serve them. (Ignore problems such as who will service the machines if everyone plugs in.) Would you plug in? What else can matter to us, other than how our lives feel from the inside? .... We learn that something matters to us in addition to experience by imagining an experience machine and then realizing that we would not use it. (Nozick, 1974, p. 42-44)

\section{Nozick provides us three reasons not to plug into the machine}

First, Nozick says that we want to do things, and not just to experience doing them. "It is only because we first want to do the actions that we want the experiences of doing them." (Nozick, 1974, p. 43) What we are matters, not just what we do. Humans crave contact with a "deeper reality". (Nozick, 1974, p.43) All of these aspects of living are stripped away when we will plug into the machine. And these parts of living seem to be ignored by utilitarianism. Nozick states that "what we desire is to live ourselves, in contact with reality". (Nozick, 1974, p.45)

This implies that we want more than just the happiness that the experience machine would be able to supply. Take an example; if one of my desires is to write a poem that people will admire, I will have a desire of the feeling of writing a poem and I would have a second desire that people are admiring my poem. Combined, both of these desires are required for writing a great poem and it bringing in the most pleasure. We would not want to plug into the machine because we believe that the second desire will not be satisfied by plugging in. Peter Singer in his video "Let's Talk About Your 
Hedonism," argues that we achieve meaning in our life through something deeper than just pursuing happiness. He says,

people that don't aim at pleasure, but aim at something else, some activity that's worthwhile in itself, and they get absorbed in the moment of doing what they're doing ... they actually get enjoyment and fulfillment out of it.

This idea directly supports Nozick's argument that humans want something deeper and more personal along with pleasure or happiness.

Second, Nozick claims that we want to be a certain sort of person. We want to express our characteristics like, courage, kindness, love etc. He writes, "Someone floating in a tank is an indeterminate blob." (Nozick, 1974, p 43)

Third, Nozick argues that plugging into an experience machine limits us to a man-made reality. According to him, a world without any real contact with our surroundings, other people, or anything of deeper significance would be repulsive to us. (Nozick, 1974, p. 645)

These are the three reasons, according to Nozick, most people would not plug into a pleasure machine. His argument against utilitarianism can be put along these lines:

Premise 1: If experiencing as much pleasure as we can is all that matters to us, then we have no reason not to plug into the experience machine.

Premise 2: We have reason not to plug into the experience machine.

Conclusion: Experiencing as much pleasure as we can is not all that matters to us.

(Premise $1 \&$ Premise 2 by Modus Tollens)
Now I will move on to critically evaluate Nozick's view regarding experience machine. Nozick's view can be challenged in many ways. He is making a fallacy of begging the question when he states, "We learn that something matters to us in addition to experience by imagining an experience machine and then realizing that we would not use it." (Nozick, 1974, p.46)

How can he conclude that we would not use the experience machine? It is, after all, a thought machine. There is no actual survey. It is true that if majority of the people are asked whether they would choose to enter the pleasure machine, their answer is probably "no". But why is the case? Is it because they have an inner desire to be in touch with deeper reality or is it the cause of something else? In his paper, If You Like It, Does it Matter if it's Real? Felipe De Brigard argues that most people may don't want to abandon their current lives not because human crave contact with a deeper reality, rather they have a psychological bias to live the life they currently know which we may call Status Quo Bias. (De Brigard, 2010, p.43) Felipe De Brigard proposes a reverse experience machine scenario in which we assume that we are already in the experience machine. Now if we are asked to disconnect ourselves from the machine, we would choose not to return to the real world because of our psychological bias. People would choose to stick with their current lives in the experience machine although they have the knowledge that their life in the machine isn't real. Brigard writes,

Part of the explanation for why most people prefer not to disconnect after spending their life in an experience machine (as in the Negative and Second Neutral vignettes) may not have to do with the virtual character of the experience, nor with the amount of pleasure they are told they would feel, but rather with the simple fact that most people don't want to 
abandon the life they know, the life they have lived so far, the life they are familiar and comfortable with. And if this explanation of my variation on Nozick's thought-experiment is accurate, then it follows that people's reluctance to plug in to Nozick's original version of the experience machine may turn out to be just an effect of the same underlying psychological bias: some people may prefer to remain unplugged, not because they value reality, but because they are averse to losing their status quo. (De Brigard, 2010, p. 51)

Adam Kolber tells us to "Imagine an investment banker with no relatives, working for twenty-five years with little or no job satisfaction. Her only pleasure in life is to come home after a twelve-hour work day and read passages from Zen Buddhist philosophers. In fact, she's come to believe that her life would be much better if she used her considerable wealth to move to Asia and study Zen Buddhism. Though she could have reason to believe that such a life would be better (given whatever conception of the good she has), she does not necessarily feel comfortable with such a drastic life change." (Kolber, 1994-1995, p.13-14)

While the investment banker feels fear at the drastic life change, the fear of plugging into the experience machine is far more greater and too strong to overcome. It is argued that if we take a survey of some people whether they would enter the experience machine, the result of the survey will not be completely accurate, because the subjects of the survey aren't answering from the position of a "confronted agent" with the feelings of confusion, worry, depression, fear or panic. So they are not in a position of giving appropriate answer to De Brigard's or Robert Nozick's experimental philosophy. Basil Smith writes:
In this scenario, subjects must envision themselves as confronted agents, with all the confusion, incredulity, fear, etc. as well as uncertainty this requires. Do they? Subjects do not have these affective reactions, nor can they imagine them. Moreover, when subjects respond (offer their survey answers), they do so as they see themselves, and this may not be a good guide to their future behaviour. In fact, the closest most subjects (or we) ever get to the reality of the problem (or to the reality of similar dilemmas) is the survey experience itself. Since this is so, experimental philosophers cannot compare the responses subjects give on a survey with their reactions to a real event (Milgram, 1974, p. 180). But without this comparison of present subject responses and future subject reactions, such philosophers can say little of interest. Therefore, in practice, certain philosophical thought experiments are impossible to test. (Smith, 2011, p. 45)

But the question arises is the inability to respond to such thought experiments in the form of a "confronted agent" necessarily a flaw in experimental philosophy? I don't think so, because our target is to know what the most morally rational decision is, not what the emotionally charged "confronted agent" would do. We all know that there is a big distinction between fact and value, that is, what one would do and what one ought to do. Nozick is making a mistake when he says that we would not use the experience machine. Just because I would not plug into the machine does not mean that I ought not to plug into the machine because we know that entering the machine will give me more pleasure than staying outside it. Suppose I am living a miserable life in reality. I have so much pain in my life. I want to pass some moments with the most pleasurable experience as much as I can get forgetting those pains. If the experience machine can able me having pleasurable experience which can reduce my pain then it would be irrational for me not to plug into the machine from the 
utilitarian perspective. Even choosing not to enter the experience machine can be consistent with utilitarianism. I may argue that staying outside the experience machine can give me more pleasure than staying into the simulated reality. For example, I would prefer to actually write a good story instead of just having the experience of writing a good story because plugging into the machine can make me "less happy" than writing it in reality. So I choose not to plug in.

Another aspect of Nozick's experience machine is about the measurement of time. He hints us to a lifetime commitment to the machine with some small breaks in order to decide what to program for the extended period of time. Nozick's argument that most people would not plug into the machine cannot be defended from practical point of view. A lifetime commitment to be plugged into the machine might not be a big deal for a person who has a very short time to live in the world. A patient of cancer might want to spend the last few days of his life with the most pleasurable experiences of such a pleasure machine. There is no point for him not to get into the machine. Moreover, Nozick states that in the experience machine we would be able to create experience as we wish, because before plugging into the experience machine we can design a picture of our experiences and after plugging in we can experience them. Thus we can make the experiences which are identical to the pleasure in reality. For example, I don't know how to climb up a mountain, but I have a keen interest to climb up. Now, if there were an experience machine in which I could set a design of climbing up a mountain, I would experience the real sufferings of climbing up a mountain and finally I could reach the top of it and would be able enjoy the beauty of the mountain, then surely I would plug myself into the machine to enjoy the pleasure of climbing up a mountain because it might not be possible in my actual life. If one can have the experience which is completely identical to the happiness in the real world, then there is no point why one wouldn't plug himself in the machine. So Nozick's claim that we would not plug into the machine because pleasure is not all that we want; we want to keep contact with a "deeper reality" is not true.

\section{Utility Monster}

Robert Nozick coined the term "Utility Monster" in response to Jeremy Bentham's philosophy of Utilitarianism. He proposed that accepting the theory of utilitarianism causes the necessary acceptance of the condition that some people would use this doctrine to justify the exploitation of others. An individual or specific group would claim more "happy units" than others deserve, and the others would consequently get fewer "happy units". Nozick calls these exploiters 'utility monsters'. He poses that utility monsters would justify their greediness with the notion that compared to others, they experience greater inequality or sadness in the world, and therefore they deserve more happy units than the others. Utility monsters would argue that the others are happier in the world to begin with, so they would not need those extra happy units to which they claim. For instance, an individual might demand 100 units of utility while others demand 1 unit of utility from any resource. In the first case, the individual can be called a utility monster. Nozick writes:

Utilitarian theory is embarrassed by the possibility of utility monsters who get enormously greater sums of utility from any sacrifice of others than these others lose ... the theory seems to require that we all be sacrificed in the monster's maw, in order to increase total utility. (Nozick, 1974, p.41)

Desire utilitarianism focuses on the evaluation of desires. It counts those desires as good that end to fulfill other desires and bad or evil those desires that tend to thwart other desires. 
Suppose we have a choice between a utility monster who receive 100 units of utility per unit of resource consumption, and one that receive 100 units of utility for each act of kindness he performs. We certainly have strong reason to prefer the second type of utility monster to the first and use our social tools to promote the formation of the second type of utility monster. That is to say, we have strong reason to call the latter 'good' and the former 'evil'.

Nozick argued that an utilitarian would require that all of the people who got lesser utility be sacrificed to the utility monster. This moral demand for sacrifice is absurd. Therefore, utilitarianism is defeated by means of a reduction to absurdity and is not morally supportive. But an objection can be raised against Nozick's argument that he presents us a frightening picture of sufferings of a society in which all people are forced to give up their happy units they deserve. His argument fails to show the emotional appeal that individuals might give up their happy units in order to make others happy. Take an example. In Bangladesh there are many starving, homeless children who can't fulfill their basic needs of food or clothing. They have a high desire to get those things. In this context all the wealthy people gain utility from keeping their food or clothing, but it is sure that the poor children can get greater utility if the wealthy people sacrifice their utility by helping those poor children. It seems like not only the utilitarians but also non-utilitarians would hold a similar position. If the wealthy people are experiencing mild unhappiness, the poor children (weak utility monsters) would be experiencing profound happiness which is greater than the sum of all people's lost utility. In this utilitarian position of giving happy units to the weak utility monsters can guarantee the increase of total happiness of a society.
Moreover, morality demands that an individual can use his conscience to make a distinction between a good desire and a bad desire. An individual may have a high desire to get highest unit of happiness but it does not necessarily follow from it that he would force others to sacrifice their happy units.

However, I think, Nozick's hypothetical position of "Experience Machine" or "Utility Monster" can't deny the practical importance of ethical hedonism or utilitarianism. I find no logical reason why a person would not plug into Nozick's experience machine, though Nozick himself said that happiness can be attained in surplus in the machine. If Nozick seems to argue that happiness is not the ultimate end and human seek a deeper reality of motivation and intentions and that a happy person is one with the motivations and intentions that a utilitarian would take as meaningless, then I should say Nozick's failed to understand the main view of utilitarianism. It is true that utilitarianism does not directly address the motivations and intentions of people, but that does not mean that utilitarianism takes them as meaningless. Similarly, Nozick's concept of utility monster can't also refute utilitarianism because any need-based morality says that someone with a greater need should receive more utility or happiness unit.

\section{Works Cited}

De Brigard, Felip. "If You Like it, Does it matter if it's real?", Philosophical Psychology, 23: 1, (2011) 43-51

Mill, John Stuart, and George Sher. Utilitarianism, Indianapolis: Hackett Pub., 2001 (reprint).

Nozick, Robert. Anarchy, State, and Utopia. New York: Basic, 1974

Kolber, Adam. "Mental Statism and the Experience Machine" Bard Journal of Social Sciences 3.3-4 (1994-1995): 10-17

Smith, Basil "Can We Test the Experience Machine?", Ethical Perspectives, (2011) 44-45 